\title{
A REPRESENTAÇÃO DO FEMININO PELO FLÂNEUR EM \\ "MULHERES", DE MARCELO GAMA
}

\section{THE REPRESENTATION OF THE FEMALE BY THE FLÂNEUR IN "MULHERES", BY MARCELO GAMA}

\author{
Elisa SEERIG ${ }^{1}$ \\ ZINANI, Cecil Jeanine Albert ${ }^{2}$
}

\begin{abstract}
RESUMO: O presente ensaio tem por objetivo discutir o poema "Mulheres", do poeta gaúcho Marcelo Gama, publicado em 1913 no Rio de Janeiro, na revista Fon-Fon!. O poema apresenta aspectos da flaneurie, em que o sujeito circula pela Avenida como curioso observador crítico das pessoas que ali se movimentam. Ao mesmo tempo, a representação das mulheres passantes que são analisadas pelo sujeito-lírico desvelam não só aspectos simbólicos da urbanidade - e sua oposição com a província -, através das referências metafóricas, mas também transfiguram os principais arquétipos femininos da época: a mulher como madona, sedutora, ou musa. Consideramos que o encerramento do poema pode representar o sentimento nostálgico legítimo do poeta, ou, ainda, consistir em ironia acerca da dificuldade humana em adaptar-se às modificações dos novos tempos e das novas mulheres por ele analisadas.
\end{abstract}

PALAVRAS-CHAVE: Marcelo Gama, flâneur, Simbolismo, mulher, arquétipos.

ABSTRACT: This article aims to discuss the poem "Mulheres", by Marcelo Gama, published in 1913 in Rio de Janeiro, in the magazine entitled Fon-fon!. The poem presents aspects of flaneurie, where the subject moves around the streets as a curious and analytic observer of the citizens. At the same time, the representations of the women who walk about and are analyzed by the lyric-speaker demonstrate not only symbolic aspects of urbanity - and its opposition to the countryside villages -, by means of metaphoric references, but also transfigure the main female archetypes of that time: the woman as a madonna, seductress or muse. We consider that the ending of the poem may represent the nostalgic feeling of the poet, or, also, consist of an irony about the human difficulty to adapt to the modifications of the new times and new women analyzed by him.

KEYWORDS: Marcelo Gama, flâneur, Symbolism, woman, archetypes.

\footnotetext{
${ }^{1}$ Especialista em Tradução - Mestranda - Programa de Pós-graduação em Letras e Cultura - Universidade de Caxias do Sul (UCS), Caxias do Sul, RS - Brasil. Bolsista CAPES. Professora EBTT em Línguas Portuguesa, Inglesa e Licenciaturas - IFRS - Campus Bento Gonçalves, RS. E-mail: eseerig@ gmail.com.

${ }^{2}$ Doutora em Literatura Comparada - UFRGS; pós-doutora em História da Literatura - PUCRS. Professora titular do Programa de Pós-Graduação em Letras e Cultura - Universidade de Caxias do Sul (UCS), Caxias do Sul, RS - Brasil. Jangada | nr. 12, jul/dez, 2018 | ISSN 2317-4722 96 |P á g in a
} 
Marcelo Gama (1878-1915) foi o poeta gaúcho que, segundo Guilhermino César, introduziu o Simbolismo no Rio Grande do Sul através de seu livro de poemas Via Sacra (1902), no qual é possível observar a tendência noturna e intimista característica desse movimento literário. Há, entretanto, poemas posteriores que destoam do padrão do autor, como por exemplo o poema "Mulheres", não exatamente por eliminar a questão simbólica das representações, mas por aplicar tom e métrica diferenciados e, por isso, inovadores.

Segundo Sebastião Uchoa Leite (1986, p. 102), o que se destaca em "Mulheres", primeiramente, é "o ritmo entrecortado e desigual, bem diverso da monocórdia e do convencionalismo estrófico de seus outros poemas". O poema, datado de 1909, foi publicado na revista Fon-fon! em 1913, período em que o Rio de Janeiro recebia influências europeias e almejava conceituar-se como metrópole semelhante às de lá. Desse modo, percebiam-se as importações do estrangeiro não só na estética da cidade (a Avenida Central havia sido inaugurada em 1905, com o intuito de remover o aspecto 'estreito' e colonial outrora presente, inspirando-se em Paris) como também no uso de termos e expressões de língua inglesa e, principalmente, francesa (AMARAL, 2010).

Em "Mulheres", composto por estrofes irregulares e versos heterométricos, Marcelo Gama posiciona o sujeito-lírico como observador que se percebe no espaço urbano de seu tempo, refletindo-o nas descrições de mulheres que propositadamente observa na rua por onde passa. Tal percepção remete ao conceito de flaneurie, termo adotado por Walter Benjamin (1994) para descrever a obra de Baudelaire (1821-1867) e suas percepções sobre Paris, que, em sua época, também passava pelas transformações da modernização nas cidades. Dessa forma, o presente ensaio pretende verificar tais aspectos, identificando o flâneur no sujeito-lírico e na sua forma de representar e interpretar as figuras femininas que descreve.

Segundo Wendell Amaral (2010, p. 103) “o poeta gaúcho recém-chegado da província, [...] é capaz de ler e traduzir em seus versos [...] os símbolos da modernidade instaurada na Capital Federal". Por isso, a Avenida gera o impacto equivalente à implementação dos boulevards representados por Baudelaire e analisados por Benjamin (1994) como flaneurie.

Se considerarmos os símbolos como representações visuais, podemos atribuir o feminino presente no poema como diretamente relacionado à imagem construída da mulher. Adequadamente, temos o homem como aquele que olha, e a mulher como sendo olhada, na posição Jangada | nr. 12, jul/dez, 2018 | ISSN 2317-4722 
de passividade tão questionada pela crítica feminista. Anne Higonnert (1991, p. 297) afirma que "a feminilidade é em parte uma questão de aparências", ao discutir a vasta produção visual referente à mulher ao longo dos séculos, que se consolida ainda mais no século XIX, por meio dos três arquétipos: madona, sedutora ou musa. Arquétipos esses que são devidamente explorados por Marcelo Gama em "Mulheres”.

Ao iniciar o poema, o sujeito-lírico já enfatiza sua masculinidade ao chamar-se de "viril", pois observa as mulheres com interesse estético, numa espécie de voyeurismo. Os "ares importantes" e o "afinado quinteto de sentidos", geram a expectativa de um discurso com propriedade:

Pela simples razão de eu ser viril e poeta que celebra, encantado, eternas bodas, olho as mulheres todas com o mais impertinente interesse de esteta.

Por isso, às três da tarde e às vezes antes, desconhecido entre desconhecidos, levo para a Avenida uns ares importantes e afinado o quinteto dos sentidos.

E fico a deambular a tarde inteira entre snobs e Apolos de pulseira.

(GAMA, 1944, p. 139)

Embora perceba seus "pares" burgueses (os snobs e Apolos de pulseira), seu olhar diverge do deles porque o revelará crítico e perscrutador (LEITE, 1986, p. 103). Nas estrofes seguintes, percebemos a oposição da comparação da mulher ao ambiente natural ("florir", "estrelas", "opalas") à sensação urbana de consumo que o sujeito-lírico vivencia, tal como a criança em loja de brinquedos.

Fico-me unicamente para vê-las

no florir do seu viço,

para senti-las, para analisá-las, do autêntico ao postiço, umas - soberbas, fúlgidas estrelas, outras — de um palor lânguido de opalas...

E enrodilhando-as em olhares ledos, 
o que se passa em mim pode ser comparado

àquele querer-tudo alvoroçado

das crianças nas lojas de brinquedos.

(GAMA, 1944, p. 139)

Além disso, as diferentes mulheres que estão na rua remetem a imagens significativas que oscilam entre dois polos: o autêntico, verdadeiro ('fúlgidas estrelas') e o postiço ('pálidas opalas'). O sujeito não estabelece uma escolha ou preferência, uma vez que deseja ambas. O movimento das mulheres da rua, que pretende ser capturado em detalhes, acontece pelo olhar do observador, remetendo a aspectos de fotografia ("enrodilhando-as", "disponho-as, ponho-as em pose") - uma outra referência aos tempos modernos representados pelo espaço urbano em questão. Percebemos que a habilidade analítica do sujeito é mesmo de quem manipula quase que palpavelmente as imagens dessas mulheres, permitindo que se compreenda a menção aos cinco sentidos (na segunda estrofe) ao observar as passantes:

Olho-as, remiro-as de alto a baixo, sigo-as, dispo-as, ponho-as em pose, impassíveis e brancas, ora aqui desvendando imperfeições ambíguas de atafulhadas ancas, ora ali descobrindo, entre êxtase e surpresa, formas definitivas de beleza.

(GAMA, 1944, p. 140)

Embora o olhar do sujeito lírico se perceba voltado às formas táteis, o poderoso flâneur enfatiza seu conhecimento pessoal acerca das passantes. Eis, talvez, um outro aspecto dos centros urbanos, a facilidade em se saber da vida alheia (seja ela verdadeira ou não).

De algumas eu já sei nomes, histórias, vidas, crônicas passionais, prestigiadas do encanto de um mistério; biografias heróicas, doloridas, escândalos banais e banais episódios de adultério.

Porém, todas as mesmas, em conjunto, maravilhoso assunto de um poema intenso, em que ando a meditar, e com um título antigo, assim ao jeito 
das inscrições dos velhos pergaminhos:

"Das perfídias que hão feito

as mulheres, os vinhos

e as cartas de jogar".

(GAMA, 1944, p. 140)

A mulher por ele descrita nas estrofes não se constitui como casta ou merecedora de devoção, e sim como aquela que, estando em sociedade, é incluída em escândalos e adultérios. É comparada, por fim, com perspicaz ironia, aos vícios da bebida e do jogo. Verificamos, portanto, a mulher como sedutora, que pode levar o homem por caminhos danosos, assim como fazem o jogo e a bebida. Anne Higonnet (1994, p. 297), ao discutir a aparência das mulheres do período, afirma: "Com o esteticismo fin-de-siècle era exuberante de sexualidade, trouxe também à superfície medos latentes do poder sexual das mulheres”. (p. 326). Tal medo do poder feminino também está presente em estrofes subsequentes do poema, em que o sujeito lírico declara que "sempre as mulheres me fizeram mal,/ porque sempre me aturdem", e que tenta em vão desvencilhar-se da rede "das tentações que estas aranhas urdem".

E aquela...

Essa farandolagem cansa, esgota

as energias do meu ser sensual,

sem feição de janota,

mas submisso à mulher quando a mulher é bela,

sempre as mulheres me fizeram mal,

porque sempre me aturdem.

A princípio eu me esforço,

Preso, envolto na rede,

das tentações que estas aranhas urdem.

Vão esforço esse esforço

Pois já me arde no sangue

um espécie de sede que abrase

outro sangue, outro ser, outro corpo mais langue.

(GAMA, 1944, p. 145)

A representação do marido como 'execrável', na estrofe abaixo, está abertamente declarada como senso-comum, o que também indica o poder de proprietário do homem sobre a mulher do período. O flanêur, que já se determina como 'viril' poeta a analisar mulheres passantes, vê no 
marido uma afronta ao poder que o primeiro já não pode exercer sobre a mulher - por ser moralmente comprometida. Ou seja, entendemos o desprezo do sujeito lírico pelo marido da mulher em questão simplesmente por ele ser casado com ela e, portanto, comprometê-la moralmente com os juramentos de lealdade do casamento. Ao mesmo tempo, é importante observar que ela não está sendo poetizada por ser "casta, inexpugnável", o que denota a irrelevância da moralidade para o flanêur, que se preocupa mais em observar o concretismo do "compasso binário" da passante. De qualquer modo, não sabemos mais dessa figura masculina - sua existência como marido já é motivo para ser desprezado.

Assim, essa que aí vai é das que estão inscritas

para esse poema tumultuário, não por ser o marido um sujeito execrável

(pois os marido são sempre hediondos

quando as mulheres são bonitas),

nem por ela ser casta, inexpugnável, mas por ser o ondular dos seus quadris redondos um compasso binário.

(GAMA, 1944, p. 140)

Os elementos característicos do movimento Simbolista, ou seja, a representação subjetiva daquilo que se observa, para que se façam apenas sugestões, expressões indiretas acerca da realidade (COUTINHO, p. 319) estão presentes ao longo das descrições das mulheres observadas pelo sujeito lírico. No excerto anterior, a ênfase para o movimento dos 'quadris redondos' pode ser interpretada como exacerbada sexualização de sua figura - mais importante do que qualquer característica subjetiva. A "cortante Agripina" é comparada a espadas, porque tem asco dos homens, estando pronta a ferí-los. Parece pouco interessar ao flanêur, já que ela se constitui no arquétipo de mulher com feminilidade desviante.

E aquela que passou é a cortante Agripina, que dos homens tem asco,

fina, fria flexível e ferina

como as espadas de Damasco.

O seu aroma há de ser acre,

e há de gostar a um verde alperce

o beijo estéril que se escolha, cerce, 
nos seus lábios de lacre.

(GAMA, 1944, p. 140)

Já Marta tem sua figura representada por termos arquitetônicos, remetendo às construções e à urbanidade de seu entorno, como em "hastes giestas", "vértices e arestas". Apesar do porte esbelto, o flanêur dá a entender que sua frieza está só na aparência: "nada tem de fria,/ e em amorosos braços se abandona". A comparação de suas olheiras com as de freiras, por sua vez, traz novamente a ironia que embeleza o poema; as olheiras de Marta não são resultado de orações ou de penitências a Deus, mas de estar ébria de amor:

E Marta, esta outra, muito mais esguia, do talhe sagital de hastes giestas, ao que murmuram, nada tem de fria, e em amorosos braços se abandona.

Toda cortada em vértices e arestas, cotovelos pontudos, lembra uma primadona linda... e desafinando nos agudos. E são, com as das freiras, lívidos grumos de lutuosa cor, suas fundas olheiras: são roxos amarantos em desfolhos; e têm cintilações metálicas seus olhos de ébria, de ébria de amor.

(GAMA, 1944, p. 141)

O flanêur se detém por mais tempo a descrever a "alabastral" Eleonora, que "surge desorientando a vida urbana" com seus olhos "fatais de basilisco" e "calculadas compunções de santa". Aqui temos a oposição dos arquétipos de madona e sedutora, sendo que o último se sobressai: trata-se de uma mulher fatal aos olhos do sujeito lírico, já que "é venenoso o vinho que ela serve, na taça de seus lábios transbordantes". Verificamos, novamente, a menção ao vinho como aquilo que remete ao pecado e à sedução. Há também a comparação aos elementos urbanos de referência, em seu "aprumo de obelisco", e a menção a Melpômene, a musa (o terceiro arquétipo feminino) da tragédia.

Grande, grave, solene, alabastral, fidiana 
surge, desorientando a vida urbana, soberba em seu aprumo de obelisco,

Eleonora,

de pupilas fatais de basilisco

e gestos musicais em tom de fá

- essa Melpômene alucinadora, com os nervos da rainha do Sabá

e calculadas compunções de santa.

Vendo-a, estremeço, porque eu amo a vida,

e lhe mora nas carnes veludosas

que a luxúria ataganta,

a alma caliginosa onde flutua

o espetro de um suicida.

O que dela irradia, isso que ela insinua,

é o mistério e o pavor das coisas tenebrosas.

É natural, portanto, que eu me enerve,

vendo-a, sob pavores delirantes:

é venenoso o vinho que ela serve

na taça dos seus lábios transbordantes.

(GAMA, 1944, pp. 141-142)

Em seguida, seu olhar se desvia prontamente a outra passante, a quem não dá nome, apenas chama de "capricho estético da graça". Essa também lhe assoma o desejo, já que o faz "pensar em gulodices". Porém, acusa-a de ser diferente das demais, atribuindo-lhe um rosto "nobre" e "litúrgico" e com aspecto de tristeza. Verificamos aqui uma possível associação ao arquétipo de madona, pelas referências religiosas concluídas nos últimos versos da estrofe: os olhos lembram "vitrais", "acho-a de estilo gótico: sugere / torres de catedrais." A urbanidade do flanêur está aqui presente em sua bela associação da mulher em questão, a ser comparada à construção religiosa emblemática das grandes cidades.

Leve, frágil, mignone, e que não anda - esvoaça, toda alegria e moda e aroma e garridices, esta - capricho estético da graça -

faz-me pensar em gulodices.

Das outras todas esta aqui difere:

pela linha ogival da sua fronte nobre, por seu rosto litúrgico, tristonho, dar-me impressões de miserere, 
e por seus olhos místicos, de sonho,

lembrarem-me vitrais,

acho-a de estilo gótico: sugere

torres de catedrais.

(GAMA, 1944, p. 142)

A menção à religião, aqui representada por uma expressão tristonha e melancólica, será retomada ao final do poema sob uma outra perspectiva.

A juventude de Mirina traz ao sujeito-lírico a sensação de envelhecimento. Comparando-a ao florescimento, percebe seu passo como "travesso", reconhecendo a transformação em mulher ao sentir "as nebulosas da fecundidade". A irmã que caminha ao lado, entretanto, é julgada pelo flanêur como "cansada" da virgindade - nesse contexto, entende-se que seja a mais velha e que há a necessidade de um casamento. De fato, reconhecemos, aqui, o conceito de que a mulher só é completa ao lado de um homem, porém, a menção à virgindade que 'cansa' insinua a possibilidade de desejo carnal à mulher, o que estava apenas começando a ser explorado.

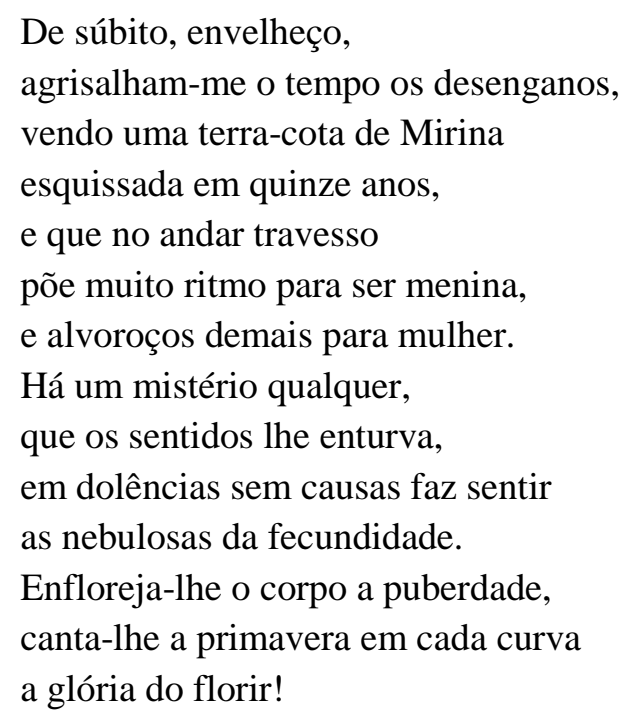

Entediada, a seu lado, entanto, a irmã revela que a virgindade já lhe vem cansando o emagrentado corpo de pucela que o tempo delusor vai devastando.

(GAMA, 1944, pp. 142-43)

A comparação da próxima mulher analisada pelo esteta, Cléo, a uma tarântula que a todos seduz, é uma estratégia de descrição do feminino já usada em outro poema seu, "Teias de aranha" 


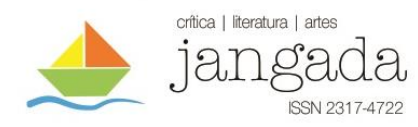

(publicado em Via Sacra). Nesta representação, a mulher é a que detém um poder maligno de sedução sobre os homens: "Cléo tiraniza, Cléo fulgura, Cléo perturba". Sua aparência é mais detalhada, mas permanecem sempre a subjetividade e o uso constante de metáforas típicos do Simbolismo, remetendo a situações de perigo e morte: as formas curvilíneas são propositadamente comparadas a uma arma (cimitarra) e o vale de seus peitos têm suspiros que "pedem asilo, e morrem". Cléo é, portanto, a mulher que a todos seduz e que, novamente, pode levar o homem ao caminho do sofrimento: ela é uma tarântula que envolve os homens, ela é cimitarra que apunhala, ela mata suspiros em seu colo. Percebemos, aqui, portanto, o arquétipo feminino de sedutora muito bem delineado.

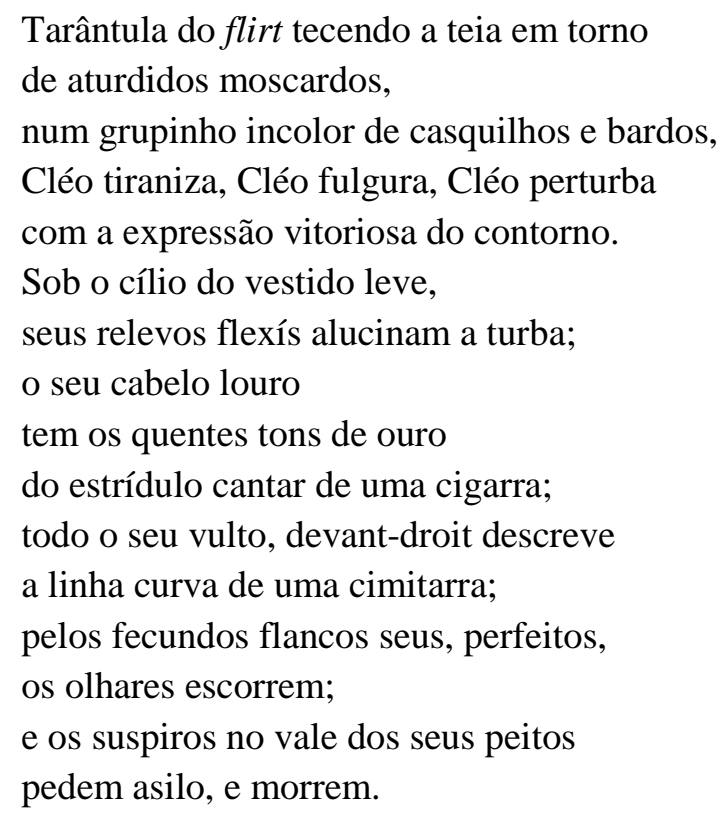

(GAMA, 1944, p. 143)

É interessante observar ainda a análise dos três primeiros versos, desenvolvida por Leite (1986, p. 105). Segundo sua interpretação, a sedução exercida pela "teia" é rompida com a crítica presente na rima moscardos/bardos, pois ela funciona como

índice do envolvimento do poeta na teia tecida pela "tarântula do flirt", e ao mesmo tempo como índice autorreferente, autocrítico e ao mesmo tempo crítico de uma determinada poética. Pois é dessa poética, néo-romântica, parnasiana, 
decadentista ou simbolista que o poeta se afasta pelo humor, pela injeção de elementos paródicos.

Distraído pela beleza de Cléo, o sujeito-lírico acaba-se impedido de ver o rosto da próxima passante e, como legítimo flanêur curioso em analisá-la mais profundamente, decide segui-la, assumindo tal atitude como um desvario justificável "só num doido ou poeta", para poder ver-lhe a face. Percebemos que o que desperta o interesse do flanêur é a estética: o "corpo lindo" e o "vestido de apurado gosto" são os aspectos que atiçam o interesse do observador; o sentido da audição também é estimulado pelo som (e pela imaginação) do roçar dos tecidos nas pernas da jovem. Ao mesmo tempo em que há o interesse carnal pela mulher em questão, o sujeito-lírico diz imaginar "um rosto de madona"... retomando a referência ao arquétipo de beleza divino e puro. Por fim, toda a sua curiosidade cai por terra ao constatar: "Fito-a... É feia!". Seu comentário final reafirma o interesse puramente estético. Muito embora em nenhum momento ele descreva claramente as feições das demais mulheres - o máximo que chega a mencionar refere-se a forma de olhar, à cor dos cabelos ou mesmo à boca, sem nunca dar detalhes objetivos - entendemos que há um critério que direciona sua análise a uma beleza física completa, dos pés à cabeça. O "defeito" do rosto ou expressão desagradável o decepcionam; poder-se-ia até dizer que o sujeito lírico se sente ludibriado, já que em seguida alega "E a radiosa teoria de Afrodite / Prossegue urdindo a trama / Das seduções que homem não há que evite.”

A olhar Cléo, distraído,

com meu impertinente interesse de esteta, daquela que lá vai não pude ver o rosto.

Deve ser bela: o corpo é lindo, e o seu vestido

é de apurado gosto...

Sigo-a... (Às vezes eu tenho uns desvarios justificáveis só num doido ou poeta!)

O damasco da saia,

roçagando-lhe as gâmbias, enrodilha-as, afaga-as, cinge-as, dando-me volutuosos calafrios...

Vejo-lhe a carne rósea, sob a meia que é de uma transparência de cambraia... Imagino-lhe um rosto de madona... 
Tão sinergicamente ela impressiona,

que apuro o passo... Alcançando-a... Fito-a... É feia!

E a radiosa teoria de Afrodite

Prossegue urdindo a trama

Das seduções que homem não há que evite.

(GAMA, 1944, pp. 143-144)

Em poucas linhas, o sujeito-lírico também propõe a pequena crítica às classes sociais ao falar de Laura, que pertence ao grupo de "gente pobre que faz vida chic", ou seja, àquelas que optam por manter as aparências - este elemento tão caro às mulheres porque também é, como vemos neste poema, tão profundamente valorizado pelos homens - mesmo sem ter condições financeiras para isso. Descreve-a ainda como tendo "modos bizarros", que domam os "corações mais frios".

Antes que o madrigal, bem merece o epigrama,

Laura, por ser do atormentado grupo

da gente pobre que faz vida chic.

Passou, e o meu olhar segue-a como um apupo, mas há nos gestos seus não sei que graça, um tic certos modos bizarros, que os corações mais frios doma.

(GAMA, 1944, p. 144)

A movimentação da rua, elemento essencial da flaneurie, volta a ser salientada ao ver surgir a próxima dama a ser analisada à porta de um bazar:

À porta de um bazar gloriosamente assoma

A Venus imortal dos amores andejos:

Madame Hortência Alvim de Paes e Barros.

Apaga-se, a seu lado, a figura da filha.

Seu dramático vulto, airoso e alto, modelado em violette e doirado por lendas, a um tempo é inferno e é céu.

Sarjam-lhe o corpo sádicos desejos

da açulada matilha

dos dons joões da alta roda,

Pois os olhares seus - luxúria ao léu -

Devassam-lhe o pudor e rompem-lhe o assalto

as muralhas dos linhos e das rendas.

(GAMA, 1944, p. 144) 
Eis a única mulher do poema que parece ser digna de ter o nome completo mencionado: "Madame Hortência Alvim de Paes e Barros." Tal diferencial delimita, conforme Leite (1986, p. 104), a alta classe social a que pertence, já que é envolta pelos desejos de "açulada matilha / dos dons joões da alta roda". O interesse tão saliente dos homens pode ser interpretado como resultado de sua aparência exuberante: "Seu dramático vulto, airoso e alto, modelado em violette e doirado por lendas, a um tempo é inferno e é céu" - novamente aqui figura a dicotomia da santidade e do pecado da figura feminina. Verificamos, no quarto verso da estrofe, que a filha fica "apagada" muito embora sua juventude devesse sobressair - o que pode levar a outra interpretação da atração exercida pela mãe. É possível que estejamos observando uma viúva com grande patrimônio, e isso desperta ainda mais interesse entre os homens.

Ivete surge destoando de Madame Hortência, pois é descrita como hetaira (cortesã), escandalosa. Poderíamos interpretá-la como prostituta, pois além de ser chamada de hetaira (da moda), é também “feliz escrava de fatais desígnios”. A última, também sem nome, apenas se diz que tudo promete através de seu olhar; ambas, aqui, a seu modo, enquadram-se no arquétipo das sedutoras.

Ei-la agora, ei-la aí, a hetaira da moda, feliz escrava de fatais desígnios, a escandalosa Ivete de glaucos olhos e cabelos ígneos.

E esta outra (que se fosse menos magra - pois é quase incorpórea como um som -

Bem pudera servir de de modelo em Tanagra) tudo a todos promete, através do lorgnon.

(GAMA, 1944, pp. 144-145)

A dicotomia de perdição e salvação retorna nos seguintes versos:

Essa é a crise suprema, a tantálica fase...

Mas aos poucos se aquieta esta alma ardente, assuste-a embora a evocação do pomo de Eva...

(GAMA, 1944, p. 145) 
Temos aqui a menção bíblica ao pecado original, sob a interpretação de ter sido conduzido pela Primeira Mulher, Eva, e o qual deve ser lembrado para que o poeta não caia na tentação das seduções de tais mulheres.

Ao final da tarde, com o sol colorindo o céu, o lusco-fusco impede nosso esteta de continuar sua minuciosa análise:

Ao esmaiar da luz perdem trapos e adornos

o prestígio da cor e das minúcias,

Já se confundem sedas e pelúcias

nos bruxoleios deste fim de tarde.

E apenas se adivinha

pelo perfeito ritmo dos contornos,

quem seja certa esguia figureta

que à meia-luz, que tudo encarde,

se esgueira recortando a fina silhueta.

(GAMA, 1944, p. 146)

Para Walter Benjamin (1994, p. 35), “a rua se torna moradia para o flâneur que, entre as fachadas dos prédios, sente-se em casa". De fato, no poema "Mulheres", observamos a autonomia e a tranquilidade analítica do sujeito-lírico a observar as passantes, suas repetidas referências a espaços e comportamentos urbanos. Porém, em uma reviravolta, nosso esteta revela que sua perspectiva de observação meticulosa, com tom de humor e desdém, esconde a nostalgia anterior à urbanidade, no encerramento do poema:

Isso é quando, num vórtice a saudade

me envolve e arrasta

Para junto da que é a inconfundível, ínscia

Do exasperado anseio da vaidade...

A que acalanta os meus lamentos...

A vitoriosa na postura casta

das místicas madonas do quinhentos...

Aquela que ficou lá na minha província...

(GAMA, 1944, p. 146)

No trecho final, percebemos, portanto, o sujeito-lírico que, embora adaptado à grande cidade emblematicamente representada pela Avenida, ainda almeja sua província - essa que ainda 
não foi 'desfigurada' pela modernidade. Da mesma forma refere-se às mulheres, já que sua referência feminina na província são as madonas castas representadas pela religião. Ou seja, “... a mulher é madona, anjo ou demônio. Mas antes de tudo ela é madona (...)” (MICHAUD, p. 146). Parece ainda impossível desvincular a mulher ideal da castidade e da religião, mesmo que antes representada com melancolia e tristeza, ou, talvez, justamente por isso.

Verificamos aqui o percurso de flaneurie ao observar as mulheres passantes em um grande centro urbano. É interessante observar que as figuras femininas não recebem voz: o que se sabe é o que é visível aos olhos do poeta, que, de fato, assume sua perspectiva de esteta e, portanto, não teria interesse em aspectos da personalidade das mulheres em questão. Ao mesmo tempo, a série de insinuações feitas delineiam os arquétipos femininos recorrentes - a mulher é sedutora, musa ou madona, através de seu olhar, feições, porte ou postura. Há menção a comentários acerca delas, há julgamentos de seus pensamentos, insinuações sobre sua seriedade, respeitabilidade, índole... ou seja, a personalidade feminina que se insinua ainda é "uma personalidade imaginada pelos homens" (HIGONNET, p. 315).

O percurso do flanêur por tamanha diversidade de mulheres é, mesmo assim, um meio de representar o distanciamento que se estaria construindo com relação aos padrões femininos; embora reconheçamos a aproximação com os três arquétipos, percebemos também que nem todas se encaixariam em apenas um deles. Ao mesmo tempo, o encerramento do poema e a menção às "madonas dos quinhentos" pode ser uma grande ironia sobre o apego que ainda se mantém, mesmo com a chegada da urbanidade, à figura idolatrada em sem máculas associada à Virgem Maria - um perfil que, finalmente, não mais sintetiza o feminino.

\section{REFERÊNCIAS BIBLIOGRÁFICAS}

AMARAL, Wendel de Freitas. Implicações do olhar moderno na obra de Marcelo Gama. 2010. 146 fl. Dissertação (Mestrado em Letras: Estudos Literários) - Faculdade de Letras, Universidade Federal de Juiz de Fora. Disponível em: https://repositorio.ufjf.br/jspui/bitstream/ufjf/2696/1/wendelldefreitasamaral.pdf Acesso em: 05. jul. 2018.

BENJAMIN, Walter. Charles Baudelaire: Um lírico no auge do capitalismo. São Paulo: Brasiliense, 1989.

GAMA, Marcelo. Mulheres. In.: . Via Sacra e outros poemas. Rio de Janeiro: Sociedade Felippe d'Oliveira, 1944. 
HIGONNET, Anne. Mulheres e imagens. In: FRAISSE, Geneviève, PERROT, Michelle. História das mulheres no Ocidente. Vol. 4: O Século XIX. Porto: Afrontamento, 1991.

LEITE, Sebastião Uchoa. Marcelo Gama: Farandulagem, Flaneurie. In.: Crítica Clandestina. Rio de Janeiro: Taurus, 1986.

MICHAUD, Stéphane. Idolatrias: representações artísticas e literárias. In: FRAISSE, Geneviève, PERROT, Michelle. História das mulheres no Ocidente. Vol. 4: O Século XIX. Porto: Afrontamento, 1991. 